\title{
Transformational leadership or effective managerial practices?
}

\author{
J. Bruce Tracey and Timothy R. Hinkin \\ School of Hotel Administration \\ Cornell University
}

Final version published in Group \& Organization Studies (1998), 23(3), 220-236 


\begin{abstract}
A study was conducted to analyze B.M. Bass and B.J. Avolio's concept of transformational leadership by comparing their Multifactor Leadership Questionnaire (MLQ) with the Managerial Practices Survey (MPS) of G.A. Yukl. The MPS advocated scales related to idealized influence, inspirational motivation, personal considerations and intellectual stimulation. On the other hand, the MPS supported four scales on managerial practices, namely clarifying, supporting, inspiring and team building. Results indicated differences between the constructs determined by the scales. Findings also showed that a composite determinant of transformational leadership supported a variance in leadership effectiveness ratings.
\end{abstract}


Transformational Leadership or Effective Managerial Practices?

Organizations invest considerable time, effort, and money into activities that are designed to gain a better understanding of the development and performance needs of employees, particularly managers and leaders. To gain a clear and thorough understanding of which leaders may benefit from specialized development programs, or how well managers are performing their jobs, accurate and reliable measurement is critical. Unfortunately, many of the measurement instruments that are used to make such decisions have not been thoroughly examined and tested by independent researchers. Thus, the information generated by these measures is suspect and does not provide a solid basis for making effective decisions. As such, careful consideration must be given to the measurement qualities of instruments that are used to make diagnostic, developmental, and evaluative decisions.

Two measures that may have developmental and evaluative utility are the Multifactor Leadership Questionnaire (MLQ), which was developed by Bass and Avolio (1990), and the Managerial Practices Survey (MPS), which was developed by Yuki (1990). On the surface, each of these measures appears to assess a unique set of leadership and managerial behaviors, and thus, may have distinct applicability. For example, the MLQ may be applicable for identifying the development needs of leaders at the top of the organizational hierarchy, whereas the MPS may be useful for providing performance feedback to middle-level managers.

However, a careful review of these measures reveals several salient similarities that blur the distinction between transformational leadership and fundamental managerial practices. In particular, Bass and Avolio $(1990,1994)$ appear to use a variety of managerial practices to define 
transformational leadership. As a result, we are left to question the viability of using the MLQ for diagnostic and developmental purposes.

In addition to the practical concerns regarding the use of these instruments, there are theoretical implications for examining measures of transformational leadership and managerial practices. One of the long-standing controversies in the study of leadership and management is the similarities and differences between these two constructs. Although no one has suggested that leaders and managers are equivalent, there has been much disagreement about the distinction. Some have argued that the two constructs are almost mutually exclusive. Bennis and Nanus (1985), for example, proposed that "managers are people who do things right and leaders are people who do the right thing" (p. 21). However, Mintzberg's (1973) classic taxonomy of managerial roles included a leader role. And as noted above, Bass and Avolio (1994) have defined transformational leadership in terms of managerial practices. Given the lack of clarity, it appears that a closer examination of the measures used to assess these constructs is warranted.

Therefore, the general purpose of this study was to examine the extent to which the MLQ and the MPS assess distinct constructs. We will begin by presenting a brief overview and comparison of the conceptual foundations of transformational leadership and managerial practices. We will then describe the similarities between Bass and Avolio's (1994) conceptualization of transformational leadership and four of the scales that are included in Yukl's (1994) integrative model of managerial practice. Finally, we will present the results from a study that examined the empirical relationships between and among the MLQ and MPS scales, and discuss the implications of our results. 


\section{Transformational Leadership}

Burns (1978) was one of the first to provide an explicit definition of transformational leadership. He proposed that the leadership process occurs in one of two ways: either transactional or transformational. Transactional leadership is based on bureaucratic authority and legitimacy within the organization. Transactional leaders emphasize work standards, assignments, and task-oriented goals. In addition, transactional leaders tend to focus on task completion and employee compliance, and these leaders rely quite heavily on organizational rewards and punishments to influence employee performance.

In contrast, Bums characterized transformational leadership as a process that motivates followers by appealing to higher ideals and moral values. Transformational leaders must be able to define and articulate a vision for their organizations, and the followers must accept the credibility of the leader. More recently, Bass and Avolio (Bass, 1985; Bass, 1990; Bass \& Avolio, 1994) have developed a theory of transformational leadership that is a culmination and extension of earlier work by Bennis and Nanus (1985), Burns (1978), Tichy and Devanna (1986), and others.

In their recent book, Bass and Avolio (1994) proposed that transformational leadership comprises four dimensions - the "Four I's." The first dimension is idealized influence. Idealized influence is described as behavior that results in follower admiration, respect, and trust. Idealized influence involves risk sharing on the part of leaders, a consideration of follower needs over personal needs, and ethical and moral conduct. The second dimension is inspirational motivation.

This dimension is reflected by behaviors that provide meaning and challenge to 
followers' work. It includes behaviors that articulate clear expectations and demonstrate commitment to overall organizational goals. In addition, team spirit is aroused through enthusiasm and optimism. The third dimension is intellectual stimulation. Leaders who demonstrate this type of transformational leadership solicit new ideas and creative problem solutions from their followers, and encourage novel and new approaches for performing work. The fourth dimension is individualized consideration. This is reflected by leaders who listen attentively and pay special attention to follower achievement and growth needs.

Although the research on transformational leadership is relatively new, there is some empirical support for the validity of Bass and Avolio's transformational leadership construct. Using the MLQ, Bass, Avolio, and their associates (e.g., Avolio \& Howell, 1992; Bass, 1985; Hater \& Bass, 1988; Seltzer \& Bass, 1990) have found significant relationships between subordinate ratings of leader effectiveness and satisfaction with their leader and transformational leadership across a number of settings. In addition, there is some evidence that transformational leadership is significantly related to other relevant outcome variables, such as follower perceptions of role clarity, mission clarity, and openness of communication (e.g., Hinkin \& Tracey, 1994).

There are, however, some concerns regarding Bass and Avolio's theoretical and empirical research. First, the conceptual distinction between transformational and other types of leadership has not been clearly articulated. For example, there are similarities between Bass and Avolio's (1994) description of individualized consideration (e.g., the degree to which a leader pays special attention to followers' individual needs) and the consideration style of leadership (e.g., the degree to which a leader acts in a supportive, friendly manner and shows concern for followers' welfare) developed by Fleishman (1953), Halpin and Winer (1957), and others. Second, the definitions of 
the Four I's are described, in part, as outcomes of leader behavior (e.g., idealized influence as behaviors that result in follower admiration, respect, and trust). Describing outcomes of leader behavior does not provide an adequate explanation or description of the relevant behavior. Finally, although there is some evidence of predictive validity, there is little empirical support for the dimensionality of the MLQ. Researchers using the MLQ (e.g., Hinkin \& Tracey, 1994; Yammarino \& Dubinsky, 1994) have found very high correlations among the dimensions and have argued that the four dimensions of transformational leadership may be best represented as a composite scale. These concerns raise questions about the ways in which transformational leadership has been conceptualized and measured.

\section{Managerial Practices}

Compared to transformational leadership, research on managerial practices has a long history in the organizational studies literature. Since the seminal Ohio State and University of Michigan studies, there have been many attempts to define effective leadership in terms of specific behavioral categories (e.g., House \& Mitchell, 1974; Luthans \& Lockwood, 1984; Mintzberg, 1973; Morse \& Wagner, 1978; Stogdill, 1974), These and other attempts to define and refine effective leadership behaviors have led to the development of several specific and narrowly defined sets of behavioral dimensions that have been labeled as managerial behaviors or practices.

In 1989, Yukl presented an integrative taxonomy that was based on research from a wide variety of studies that used both empirical and theoretical approaches for determining the content and range of effective managerial behavior. The current taxonomy includes 14 "middle-range 
behavior categories" (i.e., managerial practices) that have been operationalized in the MPS questionnaire (Yukl, 1990). Yukl argued that this taxonomy of middle-range behaviors represents most of the behaviors relevant for understanding managerial effectiveness. Indeed, the results from an extensive validation effort support this taxonomy (Yukl, Wall, \& Lepsinger, 1990). Across six separate studies, Yukl et al. found that planning, problem solving, clarifying, monitoring, and motivating behaviors had consistently high correlations with ratings of managerial effectiveness, and that each of the 14 managerial practices were significantly related to effectiveness outcomes in at least one of the studies.

As noted above, there are some striking similarities between Bass and Avolio's (1994) description of transformational leadership and other general types of leadership. In addition, there appears to be a substantial degree of similarity between the Four I's and various managerial behaviors included in Yukl's $(1989,1994)$ taxonomy. A close inspection of the definitions offered by Yukl shows that four of the managerial practices included in his integrative taxonomy — clarifying, inspiring, supporting, and team building — are defining elements of the four transformational leadership dimensions presented by Bass and Avolio. Yukl defined these four managerial practices as follows:

Clarifying: Assigning tasks, providing direction in how to do the work, and communicating a clear understanding of job responsibilities, task objectives, deadlines, and performance objectives.

Inspiring: Using influence techniques that appeal to emotion or logic to generate enthusiasm for the work, commitment to task objectives, and compliance with requests 
for cooperation, assistance, support, or resources, and setting an example of appropriate behavior.

Supporting: Acting friendly and considerate, being patient and helpful, showing sympathy and support when someone is upset or anxious, listening to complaints and problems, looking out for someone's interests.

Team building: Facilitating the constructive resolution of conflict, and encouraging cooperation, teamwork, and identification with the work unit.

For example, consider the inspirational motivation dimension. Bass and Avolio (1994) described this type of transformational leadership as behaviors that communicate expectations (clarify) and create a team spirit (team building) through enthusiasm (inspiring). Based on this definition, it may be argued that inspirational motivation is simply a blend of the clarifying, team building, and inspiring behaviors. The failure to distinguish the transformational leadership dimensions from these middle-range managerial practices is evident elsewhere. Supporting practices, such as acting in a considerate manner, listening to the concerns of others, and encouraging followers to try new approaches to problem solving, are defining elements of the individualized consideration and intellectual stimulation dimensions. These similarities make it difficult to clearly distinguish transformational leadership from the four managerial practices listed above.

However, although there appears to be a great deal of overlap, it also appears them are some unique elements of Bass and Avolio's description of transformational leadership that 
distinguish it from managerial practice. For example, the intellectual stimulation dimension includes behaviors that challenge the status quo and encourage nontraditional thinking. In addition, there is a strong future-oriented theme associated with the inspirational motivation dimension. These two examples provide some insights regarding the unique characteristics of the transformational leadership construct.

The discussion above suggests there is considerable conceptual overlap between Bass and Avolio's (1994) Four I's and four of Yukl's $(1989,1994)$ managerial practices. However, it also appears that the transformational leadership construct includes some unique qualities that distinguish it from basic managerial practice. It may be that the MLQ provides a clearer empirical distinction than that offered by the conceptual definitions of the Four I's. As such, an examination of the measures developed by Bass and Avolio and Yuki was conducted. To the best of our knowledge, this is the first effort to compare these measures.

Based on the discussion above, we developed and tested the following four hypotheses:

Hypothesis 1: The MLQ scales assess an underlying transformational leadership construct that is distinct from an underlying managerial practices construct that is assessed by the MPS scales.

This hypothesis addresses the question, Is transformational leadership distinct from managerial practices? By focusing on a scale level of analysis, we can learn whether there is a general distinction between transformational leadership and managerial practices. Although there appear to be many conceptual similarities between 
transformational leadership and various managerial practices, the MLQ may capture empirical distinctions that are not evident in Bass and Avolio's (1994) conceptualization of the Four I's.

Hypothesis 2: The MLQ measures four related, yet distinct, dimensions of transformational leadership.

Bass and Avolio proposed that although each of the Four I's were related, the dimensions are conceptually distinct. To test this proposition, an examination of the MLQ factor structure was warranted. We expected to find support for a four-factor model.

Hypothesis 3: The MPS measures four related, yet distinct, dimensions of managerial practice.

Although the primary focus of this study was to assess the extent to which the MLQ and the MPS assess distinct constructs, it was also relevant to determine if the conceptual distinctions .among the four MPS scales are empirically supported. Similar to Hypothesis 2, we expected to find support for a four-factor model of the MPS.

Hypothesis 4: The MLQ scales will account for a unique proportion of variance in leader effectiveness, above and beyond that accounted for by the MPS scales. 
Prior research has provided some evidence for the predictive validity of the MLQ (e.g., Seltzer \& Bass, 1990) and the MPS (e.g., Yukl, Wall, \& Lepsinger, 1990). If the MLQ and the MPS are indeed distinct, then each of the scales considered in the current study should account for a unique proportion of variance in ratings of leader effectiveness - an appropriate dependent variable for assessing the predictive validity of the MLQ and MPS scales.

\section{Method}

\section{Sample}

The participants in this study included 291 lower- and middle-level managers from 47 mid- to upscale hotels located across the United States. These hotels ranged in size from about 100 rooms to over 500 rooms. The average age of the respondents was 38 , and $50 \%$ were female. Most of the individuals (62\%) had been in their current jobs longer than 1 year, and most (74\%) had at least some undergraduate college experience. The managers represented all major functional areas within most U.S. lodging properties (e.g., accounting, marketing, human resources, and operations).

\section{Procedure}

The authors administered questionnaires directly to 214 of the participants. Due to the geographical dispersion of the hotels, an additional 140 questionnaires were sent to potential respondents through the mail. Of these, 77 usable questionnaires were returned (56\% response rate). There were no significant mean differences between the two groups of respondents (based 
on $\mathrm{t}$ tests) on any of the data used in this study. Therefore, all analyses were based on a total sample of 291 cases.

All participants responded on a voluntary basis and were assured that their individual responses would remain confidential. The referent leaders for this study were the participants' direct supervisors, who held positions as department heads, general managers, and regional vice presidents in their respective organizations.

\section{Measures}

Transformational leadership. Four scales from Form 5-X of the MLQ developed by Bass and Avolio (1990) were used: idealized influence, inspirational motivation, intellectual stimulation, and individual consideration. Each scale had 7 to 10 items. A total of 39 items asked respondents to indicate how frequently their immediate supervisor demonstrated the leadership behavior described. The response choices ranged from 0 (not at all) to 4 (frequently, if not always).

Managerial practices. Four scales from the MPS (Yukl, 1990) were used: clarifying, inspiring, supporting, and team building. Each scale had 5 to 6 items. A total of 22 items asked respondents to indicate the extent to which their immediate supervisor demonstrates the behavior described. The response choices ranged from 1 (never, not at all) to 4 (usually, to a great extent).

Effectiveness. To assess leader effectiveness, a 6-item scale developed by Hinkin and Tracey (1994) was used. The items asked respondents to rate the effectiveness of the leader on technical competence, interpersonal skills, procedural justice, organizational influence, communication, and goal clarification. These items reflect leader effectiveness along a single, 
broadly defined construct (cf. Campbell, Dunnette, Lawler, \& Weick, 1970). The response choices ranged from 1 (highly ineffective) to 7 (highly effective).

\section{Analyses}

First, confirmatory factor analyses of the leadership and managerial practices scales (based on mean scores) were conducted to examine the extent to which the measures assessed distinct constructs. Next, separate confirmatory factor analyses were conducted to examine the within-measure distinctions among the MLQ and MPS scales at the item level of analysis. Internal consistency reliabilities (Cronbach's alpha) were then computed, and all measures were correlated to examine the relationships among the leadership, managerial practices, and effectiveness scales. Finally, a multiple regression analysis was conducted to examine whether the MLQ scales accounted for a unique proportion of variance in leader effectiveness, above and beyond that accounted for by the MPS scales.

\section{Results}

To test Hypothesis 1, a confirmatory factor analysis of the transformational leadership and managerial practices scales was conducted using LISREL 8.03 (Jöreskog \& Sörbom, 1993). A two-factor model was tested in which the four MLQ scales were used as indicators of an underlying transformational leadership construct, and the four MPS scales were used as indicators of an underlying managerial practices construct. Model fit was evaluated using the sample variance-covariance matrix as input and a maximum likelihood solution. Overall, this two-factor model was supported. The chi-square was statistically significant $\left(X^{2}=105.47\right.$; $d f=19 ; p<.01)$, the goodness of fit index was 0.90 , the comparative fit index was 0.97 , the 
normed fit index was 0.96 , the nonnormed fit index was 0.95 , and the root mean square residual for the predicted minus observed correlation matrices was 0.02 . The significant chi-square result was not considered problematic because this statistic is particularly sensitive to sample size (cf. Bollen, 1989).

To test Hypothesis 2, a confirmatory factor analysis of the transformational leadership items was conducted. The fit of a four-factor model, in which the MLQ items were used as indicators of the respective transformational leadership dimensions, was evaluated using the sample variance-covariance matrix as input and a maximum likelihood solution. The overall chisquare was statistically significant $\left(\mathrm{X}^{2}=1,738.37 ; d f=703 ; p<.01\right)$, the goodness of fit index was 0.77 , the comparative fit index was 0.84 , the normed fit index was 0.77 , the nonnormed fit index was 0.83 , and the root mean square residual for the predicted minus observed correlation matrices was 0.08 . Because these indices were not within the range of conventionally accepted values (cf. Bollen, 1989), this four-factor model was not supported.

In contrast, the confirmatory factor analysis of the managerial practices items did support a four-factor solution. As before, the fit of the four-factor model was evaluated using the sample variance-covariance matrix as input and a maximum likelihood solution. Although the overall chi-square test was statistically significant $\left(\mathrm{X}^{2}=492.78 ; d f=203 ; p<.01\right)$, the goodness of fit index was 0.90 , the comparative fit index was 0.95 , the normed fit index was 0.91 , the nonnormed fit index was 0.95 , and the root mean square residual for the predicted minus observed correlation matrices was 0.03 . Again, although the chi-square value was statistically significant, all other indicators suggested a good model fit. 
The means, standard deviations, internal consistency reliability estimates, and intercorrelations among all the measures are shown in Table 1. The internal consistency estimates were adequate for all scales, ranging from 0.84 to 0.92 .

The results from the correlation analysis showed strong relationships between and among the MLQ and MPS scales. The correlations between the MLQ and MPS scales ranged from 0.64 to $0.82(p<.01)$, the correlations among the MLQ scales ranged from 0.81 to $0.91(p<.01)$, and the correlations among the MPS scales ranged from 0.68 to $0.81(p<.01)$.

Due to the lack of support for Hypothesis 2 and the high correlations among the MLQ scales, it may be argued that the MLQ scales are best represented by a single, transformational leadership scale. To examine this alternative, a one-factor model of the MLQ scales was examined. Using the same procedures described above, the results supported a one-factor representation. The chi-square was $105.47(d f=19 ; p<.01)$, the goodness of fit index was 0.90, the comparative fit index was 0.97 , the normed fit index was 0.96 , the nonnormed fit index was 0.95 , and the root mean square residual for the predicted minus observed correlation matrices was 0.02 . Therefore, it appears that the MLQ scales may be best represented by a composite leadership measure - a conclusion supported by previous research using the MLQ (e.g., Yammarino \& Dubinsky, 1994).

To test Hypothesis 4, a multiple regression analysis was conducted. Because the preceding results did not support distinctions among the MLQ scales, a composite measure (mean scale score) of transformational leadership was used for this analysis. The results showed that when the composite MLQ scale and the four MPS scales were entered simultaneously to predict leader effectiveness, clarifying and inspiring behaviors and the transformational 
leadership measure had significant beta weights in the regression equation $\left(R^{2}=0.75 ; F=\right.$ 146.99; $p<.01)$. The regression results are reported in Table 2.

\section{Discussion}

Sound measurement is one of the keys to making effective decisions and providing quality feedback. Today, there are many measurement instruments that can be used to assess development needs and evaluate performance of managers and leaders. To gain meaningful and useful information to make effective decisions, such instruments must have sound psychometric characteristics. The current study provides some needed insights about the measurement qualities and practical utility of the MLQ and the MPS.

The results provide mixed support for the utility of the MLQ. On the positive side, the scale-level confirmatory factor analysis supported a general distinction between transformational leadership and managerial practices. In addition, the regression analysis showed that the composite transformational leadership measure accounted for a significant proportion of variance in ratings of leader effectiveness, beyond that accounted for by the managerial practices scales. Thus, it appears that the MLQ measures a leadership construct that can be distinguished from the middle-range behaviors that are assessed by the MPS.

On the negative side, the lack of evidence for the proposed factor structure of the MLQ is quite troublesome. The results from the item-level confirmatory factor and correlation analyses did not support the Four I's notion. Although Bass and Avolio (1994) did not suggest that the four dimensions were orthogonal, they did argue that these dimensions were distinct. It appears that further refinement of the scales is necessary. A more recent version of the MLQ has been 
developed (Form 10) but was not available at the time of this study. Perhaps this newer version will provide a better distinction among the transformational leadership dimensions and provide a more precise explanation of this construct.

To address the concerns about dimensionality and the unique elements of the MLQ, a post hoc exploratory factor analyses of the MLQ items was conducted. This analysis was conducted using an oblique rotation and a principal components extraction. A scree test and Kaiser criterion (i.e., eigenvalues greater than 1.00) were used to select the number of factors, and items with factor loadings of 0.40 or higher on a single factor were used to define the factors.

The results yielded a five-factor solution that accounted for $63.1 \%$ of the variance. Twenty-eight of the initial 39 items were used to define the factors. Factor 1 included four idealized influence items, four individualized consideration items, and two inspirational motivation items. The items for this somewhat general factor focused on values, trust, success, and a sense of purpose. However, many of these items also included future-oriented qualities (e.g., "articulates a compelling vision of the future"). Factor 2 included four intellectual stimulation items that emphasized questioning assumptions and nontraditional thinking. Factor 3 included two idealized influence items and one inspirational motivation item. The idealized influence items focused on the conviction in values and consistency between values and behavior, whereas the inspirational motivation item assessed the extent to which the leader talks optimistically about the future. Factor 4 was defined by two intellectual stimulation items that were similar in content to those associated with Factor 2. Factor 5 included five individualized consideration items, three intellectual stimulation items, and one inspirational motivation item. This factor included items that focused on encouragement and the personal development of followers. 
Although this exploratory analysis was not particularly "clean," the results highlight three behavioral themes that may help distinguish transformational leadership from effective managerial practices. One theme involves questioning assumptions and nontraditional thinking. This theme is consistent with the intellectual stimulation dimension offered by Bass and Avolio, and includes collaborative problem-solving and decision-making behaviors, as well as behaviors that reflect critical evaluation and analysis. These leadership behaviors are quite distinct from the four managerial behaviors that were considered in the current study. The second theme includes a blend of the individualized consideration and idealized influence items that focus on follower development. These leadership behaviors go beyond basic consideration; they emphasize follower self-development and continuous encouragement to facilitate performance improvements. The third theme involves a future orientation. Factor 1 in particular included items that emphasized "new possibilities," "a compelling vision of the future," and a "strong sense of purpose."

Although these three themes were derived from a post hoc exploratory factor analysis, they may provide a direction for improving the distinctiveness of the MLQ. Without a doubt, there is something unique about transformational leadership. Perhaps an emphasis on behaviors that (a) involve nontraditional approaches to solving problems, making decisions, and improving work; (b) focus on the personal development of followers; and (c) promote a future orientation may be useful for refining this measure of transformational leadership and in providing additional conceptual clarity that will enhance our understanding of this leadership process.

\section{Limitations and future research}


One important limitation of the current study should be noted. The relationships among all variables may be somewhat inflated due to a single-source bias. Although Bass and Avolio (1993) noted that the correlations between the transformational leadership scales and effectiveness measures typically range from 0.60 to 0.80 , the values may have been influenced by a single-source bias. In addition, multicollinearity may explain why only two of the four MPS scales were significant predictors of leader effectiveness in the regression analysis. Thus, some care should be used when interpreting these results.

To partially address this potential bias, we conducted a supplementary correlation analysis to examine whether similar results could be obtained using an alternative data source for the effectiveness criterion. Independent ratings of job performance were collected for 33 of the referent leaders from one of the participating organizations. Performance ratings were provided by leaders' direct supervisor, and mean scores were based on a standardized, 20-item form that assessed several broad dimensions of job performance (e.g., communication and planning). Aggregate scores for the composite transformational leadership scale and the four managerial practices scales were calculated from the subordinate evaluations $(N=158)$ of the 33 focal leaders. The aggregate scores were then correlated with the job performance scores. Correlations were significant for the following scales: 0.35 for transformational leadership $(p<.05), 0.30$ for clarifying $(p<.10)$, and 0.41 for inspiring $(p<.05)$. In addition, the correlation between the performance appraisal scores and aggregate ratings of leader effectiveness was $0.36(p<.05)$. Thus, a similar pattern of results was found using an effectiveness outcome measure collected from an independent data source. This result, as well as the significant relationship between the effectiveness and performance appraisal measures, provides an added degree of confidence in the current results. 
In a little over a decade, a great deal has been learned about transformational leadership. It appears that Bass and Avolio are well on their way to developing a comprehensive framework and measurement instrument that explains the relevance and importance of transformational leadership. Refinement of the MLQ should be based on a deductive theoretical approach and should focus on the development of items that capture distinctive conceptual elements of transformational leadership. This type of effort should yield a useful tool that can be used to make substantive decisions and solve practical problems. Furthermore, the work by Yukl and others provides an important referent for understanding transformational leadership and the relationship between leadership and management.

In addition to research that provides a clearer conceptual and empirical definition of the construct domain, one suggestion for future research is to examine the process by which transformational leaders exert their influence. For example, prior research has shown a direct relationship between transformational leadership and follower ratings of satisfaction with their leader (e.g., Seltzer \& Bass, 1990). However, one reason followers may be satisfied with a transformational leader and view the leader as effective is that the leader is able to articulate and clearly describe the followers' role in accomplishing the vision. This proposition suggests that transformational leaders have a direct influence on follower perceptions of role and mission clarity and that the these perceptions subsequently influence follower perceptions of leader effectiveness. That is, the effectiveness of a transformational leader may be contingent on the ability to effectively communicate the followers' role in fulfilling the overall organizational goals and objectives. This contingency perspective is consistent with the theoretical propositions of Tichy and Devanna (1986) and the work by Yukl (1994) and should be considered in future research efforts. 
In addition, rigorous validity assessments of transformational leadership and managerial practices measures should be conducted. In addition to typical construct validity assessment procedures, Schriesheim, Powers, Scandura, Gardiner, and Lankau (1993) proposed using a Qmethod approach (cf. Q-sorts, Nunnally, 1978) to assess an instrument's "conceptual adequacy." One variation of this method requires respondents to rate questionnaire items for specific, preestablished content categories or dimensions. Responses may then be sorted and analyzed in a variety of ways (e.g., factor analysis and ANOVA) and can be used to assess the extent to which items uniquely assess a single dimension of the focal construct. This technique may be quite useful for scale development and refinement.

Finally, a multilevel framework of transformational leadership and managerial practices should be explored. Although some initial work has been conducted in this area (e.g., Avolio \& Bass, 1995), attention should be given to the ways in which various transformational leadership, and even managerial behaviors, affect individual, group and organizational outcomes. Research that incorporates a multiple level of analysis framework has a great deal of potential for understanding the contingencies of effective leadership and management. 
Table 1. Means, standard deviations, internal consistency, reliability estimates, and intercorrelations for all measures.

\begin{tabular}{|c|c|c|c|c|c|c|c|c|c|c|c|c|}
\hline & Mean & SD & $\alpha$ & 1 & 2 & 3 & 4 & 5 & 6 & 7 & 8 & \\
\hline 1. Idealized influence & 2.30 & .87 & .89 & - & & & & & & & & \\
\hline 2. Inspirational motivation & 2.45 & .89 & .91 & .91 & - & & & & & & & \\
\hline 3. Intellectual stimulation & 2.13 & .79 & .89 & .83 & .84 & - & & & & & & \\
\hline 4. Individualized consideration & 2.19 & .98 & .92 & .84 & .87 & .81 & - & & & & & \\
\hline 5. Clarifying & 3.17 & .75 & .92 & .69 & .68 & .66 & .70 & - & & & & \\
\hline 6. Inspiring & 2.99 & .75 & .90 & .82 & .81 & .73 & .79 & .73 & - & & & \\
\hline 7. Supporting & 3.20 & .77 & .91 & .67 & .70 & .64 & .78 & .68 & .73 & - & & \\
\hline 8. Teambuilding & 3.15 & .76 & .90 & .75 & .76 & .72 & .80 & .70 & .78 & .81 & - & \\
\hline 9. Leader effectiveness & 5.18 & 1.28 & .90 & .76 & .79 & .72 & .83 & .74 & .76 & .77 & .76 & - \\
\hline
\end{tabular}

NOTE: All correlations are significant at $p<.01$ 
Table 2. Results from multiple regression analysis

\begin{tabular}{lccc}
\hline Dependent Variable & Beta Weights & $\mathrm{F}$ & $\mathrm{R}^{2}$ \\
\hline Leader effectiveness & & & \\
Clarifying & $.19^{*}$ & & \\
Inspiring & .07 & & \\
Supporting & $.27^{*}$ & & \\
Team building & .05 & & .75 \\
Transformational leadership & $.09 *$ & 146.99 & \\
& & &
\end{tabular}




\section{References}

Avolio, B. J., \& Bass, B. M. (1995). Individual consideration viewed at multiple levels of analysis: A multi-level framework for examining the diffusion of transformational leadership. Leadership Quarterly, 6, 199-218.

Avolio, B. J., \& Howell, J. M. (1992). The impact of leader behavior and leader-follower personality match on satisfaction and unit performance. In K. E. Clark, M. B. Clark, \& D. R. Campbell (Eds.), Impact of leadership. Greensboro, NC: Center for Creative Leadership.

Bass, B. M. (1985). Leadership and performance beyond expectations. New York: Free Press.

Bass, B. M. (1990). From transactional to transformational leadership: Learning to share the vision. Organizational Dynamics, 18, 19-31.

Bass, B. M., \& Avolio, B. J. (1990). Manual for the Multifactor Leadership Questionnaire. Palo Alto, CA: Consulting Psychologists Press.

Bass, B. M., \& Avolio, B. J. (1993). Transformational leadership: A response to critiques. In M. M. Chemers \& R. Ayman (Eds.), Leadership theory and research: Perspectives and directions. San Diego, CA: Academic Press.

Bass, B. M., \& Avolio, B. J. (1994). Improving organizational effectiveness through transformational leadership. Thousand Oaks, CA: Sage.

Bennis, W. G., \& Nanus, B. (1985). Leaders: The strategies for taking charge. New York: Harper \& Row.

Bollen, K. A. (1989). Structural equations with latent variables. New York: John Wiley.

Burns, J. M. (1978). Leadership. New York: Harper \& Row. 
Campbell, J. P., Dunnette, M. D, Lawler, E. E., \& Weick, K. E. (1970). Managerial behavior, performance, and effectiveness. New York: McGraw-Hill.

Fleishman, E. A. (1953). The description of supervisory behavior. Personnel Psychology, 37, 16.

Halpin, A. W., \& Winer, B. J. (1957). A factorial study of the leader behavior descriptions. In R. M. Stogdill \& A. E. Coons (Eds.), Leader behavior: Its description and measurement (pp. 39-51). Columbus: Bureau of Business Research, Ohio State University.

Hater, J. J., \& Bass. B. (1988). Superiors' evaluations and subordinates' perceptions of transformational and transactional leadership. Journal of Applied Psychology, 73, 695702.

Hinkin, T. R., \& Tracey, J. B. (1994). Transformational leadership in the hospitality industry. Hospitality Research Journal, 18, 49-63.

House, R. J., \& Mitchell, T. R. (1974). Path-goal theory of leadership. Contemporary Business, 3, 81-98.

Jöreskog, K. G., \& Sörbom, D. (1993). LISREL 8.03. Chicago: Scientific Software International.

Luthans, F., \& Lockwood, D. L. (1984). Toward an observation system for measuring leader behavior in natural settings. In L G. Hunt, D. Hosking, C. A. Schriesheim, \& R. Stewart (Eds.), Leaders and managers: International perspectives on managerial behavior and leadership (pp. 117-141). New York: Pergamon.

Mintzberg, H. (1973). The nature of managerial work. New York: Harper \& Row.

Morse, J. J., \& Wagner, F. R. (1978). Measuring the process of managerial effectiveness. Academy of Management Journal, 21, 23-35.

Nunnally, J. C. (1978). Psychometric theory (2nd ed.). New York: McGraw-Hill. 
Schriesheim, C. A., Powers, K. J., Scandura, T. A., Gardiner, C. C., \& Lankau, M. J. (1993). Improving construct measurement in management research: Comments and a quantitative approach for assessing the theoretical adequacy of paper-and-pencil survey-type instruments. Journal of Management, 19, 385-417.

Seltzer, J., \& Bass, B. M. (1990). Transformational leadership: Beyond initiation and structure. Journal of Management, 16, 693-704.

Stogdill, R. M. (1974). Handbook of leadership: A survey of the literature. New York: Free Press.

Tichy, N. M, \& Devanna, M. A. (1986). The transformational leader. New York: John Wiley. Yammarino, F. J., \& Dubinsky, A. J. (1994). Transformational leadership theory: Using levels of analysis to determine boundary conditions. Personnel Psychology, 47, 787-811.

Yukl, G. A. (1989). Leadership in organizations (2nd ed.). Englewood Cliffs, NJ: Prentice Hall. Yukl, G. A. (1990). COMPASS: The Managerial Practices Survey. New York: Author/Manus Associates.

Yukl, G. A. (1994). Leadership in organizations (3rd ed.), Englewood Cliffs, NJ: Prentice Hall. Yukl, G. A, Wall, S, \& Lepsinger, R. (1990). Preliminary report on validation of the managerial practices survey. In K. E. Clark \& M. B. Clark (Eds.), Measures of leadership (pp. 223238). West Orange, NJ: Leadership Library of America. 